\title{
Postsecondary Instructors' Reflective Teaching Practices Pertaining to Gender Differences and Teaching Experience
}

\author{
Norah Almusharraf ${ }^{1}$ \\ Prince Sultan University, Riyadh, Kingdom of Saudi Arabia
}

Asma Almusharraf

Imam Mohammad Ibn Saud Islamic University (IMSIU), Kingdom of Saudi Arabia

\begin{abstract}
Reflection and reflective practices are integral to teacher education; therefore, this study contributes to the growing literature on reflective practice by uncovering gender differences. The study explored the influence of gender differences and teaching experience on postsecondary instructors' conscious reflective teaching practice, using a survey of 226 male and 207 female EFL instructors working in the Kingdom of Saudi Arabia (KSA). The results indicated that females scored higher than males on the total English Language Teaching Reflection Inventory (ELTRI) scores, except on the critical factor of the ELTRI, where males outperformed. The results also revealed that experienced instructor participants had a significantly higher score on the total ELTRI than novice instructor participants. The study proposes a tangible, flexible resource for reflective practices of applied, cognitive, affective, metacognitive, and critical reflection, and offers assistance to counter gender differences. The study recommends designing guides with effective and valid instruments for fostering reflective teaching practices. Policymakers in higher institutions should prepare systematic programs and provide remedial resources and events for instructors to target the most challenging areas for both genders. Future research should also consider other factors, such as the academic degree, cultural background, and linguistic differences that might affect the instructors' knowledge and reflective practice.
\end{abstract}

Keywords: Education level, gender, instructors' reflection, reflective practices, Saudi Arabia, teaching experience.

Reflection is an essential characteristic of proficient instructors, a significant element in the instructor's training programs, and a factor that significantly influences teaching practices. Reflective teaching is an approach involving active and continuous recognition (Zeichner \& Liston, 1996), self-examination of own teaching, and learning values and beliefs (Sifakis, 2007). Through reflection, instructors are involved in conscious thinking while monitoring their teaching practices to bring about positive changes and learn from their own professional experience (Farrell, 2015; Farrell \& Kennedy, 2019; Sifakis, 2007). Reflective thinkers are consistently conscious of what they are learning, regularly monitor what they currently know and what they should know, and realize how to bridge the gap of learning situations (Darling-Hammond et al., 2020).

Researchers have made seminal contributions (Akbari, 2007; Hoban, 2000; Jay \& Johnson, 2002) to conceptualize frameworks for reflection and reflective practices (e.g., reflective teaching).

${ }^{1}$ Corresponding Author E-Mail: nmusharraf@psu.edu.sa 
However, previously assessed studies are devoted to reporting reflective practice actions, and there is a minimal extent deliberated to address gender differences, especially in a context where English is taught as a foreign language. Although reflection and reflective practices are integral to teacher education, it stands to reason that instructors, regardless of gender and years of experience at all points of their career, could benefit from such a method.

Akbari (2007) argued that "teaching is not a neutral activity, and it is inextricably related to broader social issues, issues such as justice, race, gender, poverty, discrimination" (p.193).

Fendler (2003) asserted that a reflective movement is a feminist act (i.e., females' capacity to reflect vocally and verbally is a characteristic). The primary hypothesis here is that expert knowledge is generally produced and controlled by male authorities, putting females in a subordinate role (p. 19). Reflection is further viewed as a more feminine approach that was forced behind the rise of the reflective movement in education (Easton, 2018).

\section{Literature Review and Theoretical Framework}

The central conceptualization of reflection goes back to Dewey (1931), Schön (1987), and Van Manen (1994), who provided a meaningful framework for reflective practice. Since then, the reflective practice movement started expanding to the teaching realm, mainly in English language classrooms. The concept of reflection originated in the early 1930s by Dewey (1931) as a central role in learning and continued to progress into various practices, including the application of Bloom's (1956) taxonomy of instructional objectives, Schön's (1983) reflective practice, and Biggs's (1999) recommendations of quality teaching and learning at a college level. Rodgers (2002) described reflection as a meaning-making process that demands attitudes and actions that appreciate individuals and the community's personal and academic development. The role of reflection in teachers' development has been acknowledged in the literature (Larrivee, 2000; Rodgers, 2002). Within the concept of reflective practices, instructors' learning is considered a lifelong process where instructors must be responsible for their professional growth.

There has been a wide-ranging amount of research on reflective practice for preservice (novice) instructors who begin understanding and constructing their professional identities (e.g., Everett, 2013; Knapp, 2012; LaBelle \& Belknap, 2016; Yoshihara et al., 2020). By utilizing reflection methods in their teacher education program, acquaintances are realized between theory and practice, helping novice instructors associate their education with their real-life teaching experiences (Everett, 2013; Tsui, 2005, 2009). Through reflective practices, education is seen as a social and cultural practice, underlining the prominence of reflecting in action. Although reflection should be assimilated into preservice teacher education, it is recommended that reflection be scaffolded and guided through feedback and mentoring from more experienced educators (Candy et al., 1985; Van Manen, 1994). Reflective teaching practices are needed for all levels of educators to achieve this successfully.

\section{Experiential Learning Theory}

This current study is grounded in Kolb's (1984) experiential learning theory that defines learning as a development in which views are substantial and continually enhanced by experience. Kolb (2015) associated the construction and restructuring of viewpoints to experiential learning that stresses constant reflection through active investigation within the classrooms (i.e., new knowledge, skills, or attitudes). Kolb asserts that the learning cycle model involves four cyclic steps: concrete experience (CE), reflective observation (RO), abstract conceptualization (AC), and active experimentation (AE) that work in sequence to lead to experiential learning. Kolb's model 
is highly useful in understanding instructors' learning processes. Instructors can begin by having an experience (CE) and then reflecting on that experience from several perspectives (RO). Subsequently, instructors can draw conclusions and relate them to theories and concepts (AC) that can finally lead to experimentation and action (AE).

The reflection process is in line with Schön's (1983) reflection-in-action, which might lead to a multitude of applied apprehensions of the possible learning worth of a more "stream of consciousness" (p. 278) form of reflection that occurs during the specific period. On the other hand, reflection-on-action includes thinking back on events while reflection-in-action is 'thinking on your feet" (Schön, 1983, p. 61). According to Richert (1990), reflective practice is captured in the ability to think about what one does and why, that is, evaluating past actions, current status quo, and intended consequences. Furthermore, reflecting at the moment could lead to diverse insights and discoveries. For instructors working longer in the field, reflecting on different opinions may encourage them to develop long-standing teaching behavior, leading to comprehensive progress for both the instructor and the students.

\section{Empirical Studies Related to Gender and Reflective Practices}

When comparing gender reflective practices, several studies suggest that male EFL instructors outperformed their female counterparts regarding reflective teaching (Afshar \& Farahani, 2015; Ring et al., 2016); conversely, other studies have found no direct effect of gender on cognitive reflection (i.e., Aldahmash et al., 2017; Bawaneh et al., 2020; Dewaele et al., 2018; Primi et al., 2018). These inconsistent findings necessitate the need for further research validation to inaugurate much-needed strategies for promoting gender diversity.

The previously reported discrepancies are just some cases of the dramatic gender variances in educational professions. It is vital to note that there is no evidence that these discrepancies can be elucidated by gender differences in skills or personality traits (Kollmayer et al., 2018). Considering the individual factors, research has found that gender does not directly influence instructors' awareness of self-efficacy; however, females may have a stronger sense of efficacy than males because the teaching profession is mainly a female occupation (Gencer \& Cakiroglu, 2007).

Further, regardless of gender, teaching practice is an influential factor in reflective practice because experienced instructors are more effective at employing reflective practice than their novice counterparts (Moradkhani et al., 2017). In other words, the more experienced the instructor, the more critical reflection they reported, supporting extant literature (Dewaele et al., 2018). According to Farrell (2012), novice instructors are those who have three years of English teaching experience; after having completed their language teacher education program. Nevertheless, the consequence of practice diminishes over time because, as instructors develop practice, their selfefficacy beliefs become more or less firm. The first few years of teaching are vital for professional development, as novice instructors either reinforce their competency as instructors or change their profession (Farrell, 2009).

Recent studies have indicated that social justice is critical in classroom interactions and teacher development (Dyches \& Boyd, 2017). The research argued that reflective activities must be activated by examining, reviewing, and comprehending the need to build metacognition skills as individuals (Lundgren et al., 2017). It is central to note that the length of experience without ongoing reflection might lead to repeated teaching practices and does not necessarily give awareness and an understanding of one's teaching practice (Aalto et al., 2019). Richards (1998) explains that novice instructors do not directly apply the knowledge they gained in preparation 
courses because, as instructors, they have to construct and reconstruct "new knowledge and theory through participating in specific social contexts and engaging in particular types of activities and processes" (p. 164). On reflection, novice instructors found that practice teaching experiences that approximated "real" teaching were the most valuable part of their preparation programs (Faez \& Valeo, 2012).

Farrell (2004) viewed reflection as a holistic approach that incorporates the logical, cognitive, and metacognitive, spiritual, ethical, and emotional characteristics of teaching. Reflection types are either on-action or in-action as they relate to instructors' past and existing demands; according to Schön (1983), "We reflect on the action, thinking back on what we have done to discover how our knowing-in-action may have contributed to an unexpected outcome" (p. 26). In other words, reflection-on-action entails the practitioner thinking about his/her previous teaching experiences and evaluating future development. On the other hand, reflection-in-action entails instructors' conscious thinking (i.e., self-reflection) and amendment while on the profession (Farrell, 2012). Correspondingly, Van Manen (1994) recommended the third type of reflection, reflection-for-action, which can be defined as reflection before action. For instance, instructors use reflection to resolve issues that occur at the time of teaching and reflect on possible difficulties or conditions that may happen in their future teaching. Through reflection-for-action, BurhanHorasanlı and Ortaçtepe (2016) argued that reflective practitioners could recognize their strengths and weaknesses, assess the strategies or practices they employ in their classrooms, and accordingly increase their teaching practices by overcoming projected issues or situations.

A more comprehensive description of reflective practice can be found in Akbari et al.'s (2010) study, which included analysis stage of six overarching components of reflection: First, the Practical element, which includes reflective practice (i.e., journal writing, lesson reports, audio and video recordings, observation, action research, teaching portfolios, or analyzing critical incidents (Richards \& Farrell, 2005). Second, the cognitive element, which is concerned with instructors' attempts aimed at professional development (i.e., attending conferences and workshops related to one's field of study and reading the professional literature are among the behaviors). Third, the learner element affective, which includes the instructor reflecting on his/her students, how they are learning, and how learners respond or behave emotionally in their classes. Fourth, meta-cognitive elements, which deals with instructors and their reflections on their views and characters, how they describe their practice, and their expressive structure. Fifth, the critical element includes sociopolitical aspects of instruction and reflections, including race, gender, and social class. Sixth, the Moral element, which is connected to instructors encouraged to think critically about their purposes and justify them from a moral perspective.

Moghaddam et al. (2019) indicated that the instructors most frequently used reflective techniques were metacognitive and cognitive components, and the least frequently used were practical components. Similarly, it was determined that female students employ cognitive, metacognitive, and social strategies more recurrently than male students (Khazaie \& Mesbah, 2014; Oxford \& Nyikos, 1989). There are also significant differences in their study between the males and the females in their use of memory, cognitive, and compensation strategies. Additional studies to understand more completely the critical tenets of gender differences are required to validate previous research findings and explore commonly used reflective strategies.

Furthermore, the use of internet communication technologies is becoming progressively more predominant to encourage instructors' reflective practice using blogs and electronic dialogue journals via e-mails (Burhan-Horasanlı \& Ortaçtepe, 2016; Phelps et al., 2004). Further, as the online platform became the primary tool in teaching, learning management systems (e.g., Blackboard, Desire2Learn, and Moodle), online discussion forums and blogs could be utilized to share, assess and restructure experience within online communities of practice (Pedro et al., 2012). 
A study that examined 67 instructors' blog reflections revealed that blog reflections produced a far greater depth of reflection (Harland \& Wondra, 2011). However, both old-fashioned (e.g., reflective journaling, autobiographies, action research, annotations, classroom observations, and teacher development groups) and technology-oriented tools (e.g., blogs) have been proposed to develop the extensiveness and complexity of instructors' reflective practice. Recognizing the impact of instructors' teaching experience and life situation and the effects of the organizational and cultural contexts in which they work to maximize their professional growth is essential (Day, 1993).

This study contributes to the growing literature on reflective practices' groundwork by uncovering gender differences. The current paper explores whether gender is a factor in reflective practices by examining the gender differences in in-service postsecondary English as a foreign language (EFL) instructors' reflective teaching practices for professional development. More specifically, the research aims to answer these research questions:

1. Is there any significant difference between male and female EFL instructors regarding conscious, reflective teaching?

2. What strategies do EFL instructors mostly employ to reflect on their practice?

3. Does teaching experience significantly make a substantial variance in instructors' conscious reflection among participants of both genders?

\section{Method}

The descriptive research study explores the influence of gender differences and teaching experience on postsecondary instructors' conscious, reflective teaching practice. Mainly this study focuses on Kolb's (1984) experiential learning cycle, including four phases from problem finding to question asking, answer-seeking, and then active experimentation. The study recruited 226 male and 207 female EFL instructors working in Saudi Arabia, with an average age of $41(S D=6.3)$, ranging from 25 to 60 . These instructors were chosen based on teaching one or more English classes at the university level. The instructors were randomly recruited from university level instructors around the kingdom of Saudi Arabia. Novice instructors are the ones who have three years of English teaching or less after having completed their language teacher education program (Farrell, 2012). Therefore, this study's participants were grouped into two groups: novice (1-3 years) and experienced ( $\geq 4$ years). The setting, along with all the public and private education institutions of $\mathrm{KSA}$, is gender-segregated. The KSA educational system is an open and equal, but separate collection of public and private schools from elementary to college levels for female and male students (Alrashidi \& Phan, 2015).

\section{Instrumentation}

\section{English Language Teaching Reflection Inventory (ELTRI)}

The study utilized a questionnaire called the English Language Teaching Reflection Inventory (ELTRI) adapted from Akbari et al. (2010). This questionnaire contains 35 items in five subscales, which assess participants' reflective practices. The first subscale is a practical reflection, which includes instructors' consultations with their peers of teaching concerns, observing other instructors' classes or being observed by other instructors, and writing reflective diaries about their teaching activities. The subscale contained seven items of practical reflection (e.g., I talk about my 
classroom experiences with my colleagues and seek their advicelfeedback). The second one is a cognitive reflection, including instructors attending seminars containing seven statements (e.g., $I$ think of using/introducing new teaching techniques in my classes). The third subscale is an affective reflection, which contains instructors trying to comprehend their learners' backgrounds and identify their thoughts and expectations about various teaching activities. It had seven statements (e.g., $I$ think about my students' emotional responses to my instructions). The fourth subscale is a metacognitive reflection, which consists of instructors' attitudes toward the philosophy of teaching, critical evaluation of their teaching, and perceptions of their own previous instructors' teaching approaches. It had seven statements (e.g., as a teacher, I think about my teaching philosophy and the way it is affecting my teaching). The last subscale was critical reflection connected to instructors' knowledge of the social and political issues affecting the teaching development and the classroom setting. It had seven statements (e.g., I think about instances of social injustice in my own surroundings and try to discuss them in my classes). This questionnaire used a 5-point Likert scale with potential answers ranging from (1) "never" to (5) "always". Cronbach's alpha for these subscales ranged from .75 and .89. A reliability coefficient of 0.70 or higher is considered "acceptable" in most social science research situations (Trizano-Hermosilla, \& Alvarado, 2016; Vaske, Beaman, \& Sponarski, 2017). The questionnaire included demographic data (years of teaching, gender, and field of educational studies).

The survey was developed and disseminated from March to July of 2020 using the LimeSurvey online platform. Initially, survey participants were acknowledged (within the welcome letter) that completion of the survey indicated their agreement to participate in this research under applicable conditions (i.e., being EFL instructors and having at least one year of teaching experience at the university level). Participants were also informed that data collection would be confidential, and all personal information would be de-identified. For this study, official approval was obtained from the university's Institutional Review Board (PSU IRB-2020-04-0037).

\section{Data Analysis}

A quantitative method using inferential statistics (i.e., independent sample $t$-test, descriptive statistics, and group statistics for gender differences was utilized. The analysis was conducted utilizing SPSS statistical software. The mean score and Pearson correlation results were used to measure the values and relationships among variables. Next, normality testing was carried out. Mahalanobis and Cook's distances were run for each reflection level, and 19 outliers identified were then removed. Normality and collinearity testing were carried out to check if assumptions were correct. Tolerance levels were above .85, and all VIF values were between 1.1 and 1.2, indicating collinearity.

\section{Results}

This section summarizes the findings and contributions made. An independent sample $t$ test was used to answer the first research question: Is there any significant difference between male and female EFL instructors regarding conscious reflective teaching? As shown in Table 1, females scored higher than males on the total ELTRI score and the scores for the practical, cognitive, and metacognitive factors of the ELTRI, while males scored higher than females on the critical factor of the ELTRI. Specifically, female participants $(M=3.28, S D=0.53)$ demonstrated a significantly higher score than male participants $(M=3.19, S D=0.43)$ on the ELTRI, $t(399)=1.99, p=.049$. Female participants $(M=3.05, S D=0.61)$ demonstrated a significantly higher score than male participants $(M=2.90, S D=0.70)$ on the practical factor of the ELTRI, $t(429)=2.42, p=.016$. 
Further, female participants $(M=3.36, S D=0.74)$ demonstrated a significantly higher score than male participants $(M=3.08, S D=0.65)$ on the cognitive factor of the ELTRI, $t(413)=2.42, p<$ .001 . Female participants $(M=3.65, S D=0.70)$ demonstrated a significantly higher score than male participants $(M=3.30, S D=0.59)$ on the metacognitive factor of the ELTRI, $t(405)=5.72$, $p<.001$. On the other hand, male participants $(M=3.37, S D=0.63)$ demonstrated a significantly higher score than female participants $(M=3.07, S D=0.85)$ on the critical factor of the ELTRI, $t(379)=-4.04, p<.001$.

Table 1

Descriptive Statistics for Gender Differences

\begin{tabular}{lcccc}
\hline & Gender & $\mathrm{N}$ & $M$ & $S D$ \\
\hline ELTRI - Total & female & 207 & 3.2792 & .52506 \\
& male & 226 & 3.1875 & .43180 \\
ELTRI - Practical & female & 207 & 3.0523 & .60769 \\
& male & 226 & 2.8997 & .70274 \\
ELTRI - Cognitive & female & 207 & 3.3559 & .73701 \\
& male & 226 & 3.0833 & .65457 \\
ELTRI - Learner & female & 207 & 3.1804 & .82419 \\
& male & 226 & 3.2965 & .70771 \\
ELTRI - Metacognitive & female & 207 & 3.6549 & .69746 \\
& male & 226 & 3.2977 & .59258 \\
ELTRI - Critical & female & 207 & 3.0745 & .84607 \\
& male & 226 & 3.3666 & .63170 \\
\hline
\end{tabular}

A descriptive statistical analysis was also conducted to answer the second question: What strategies do EFL instructors mostly employ to reflect on their practice? The data analysis demonstrated that the most frequently used strategy among Saudi instructors was metacognitive strategies, which comprised $76.8 \%$ of females leaning towards using this approach more often than other strategies, mainly reflecting over their strengths and weaknesses as instructors. With a slightly lower percentage $(73.9 \%)$ than their female counterparts, males most often try to assess which aspects of their teaching provide them with a sense of satisfaction. For example, female instructors indicated that they often think about their strengths and weaknesses as instructors; however, they rarely think of the teaching job's meaning or significance. On the other hand, male instructors often try to explore which aspects of their teaching provide a sense of satisfaction; however, they rarely think about their strengths and weaknesses.

Closely following metacognitive strategies, critical strategies were the second most frequently used strategy among male instructors $(73.5 \%)$. Male instructors reported thinking about their teaching's political aspects and how it may affect their students' political views. Still, they rarely think of ways to promote tolerance and democracy in their classes and society. On the other 
hand, females' second-most used strategy was reported to be learner/affective strategies (67.1\%). For instance, female instructors reported that they often talk to their students to learn about their learning styles and preferences but rarely talk to them to learn about their family backgrounds, hobbies, interests, and abilities.

Concerning the learner/affective strategies, males $(66.8 \%)$ reported using them as the third most frequently used type of strategy. This involves reflecting upon their students, notably asking whether they like a teaching task or not. Male instructors participating in this study indicated that they often ask their students whether or not they like a teaching task but rarely talk to their students to learn about their learning styles and preferences. However, $61.8 \%$ of the female participants used cognitive strategy as the third most used strategy, consisting of writing articles based on experience. In detail, female participants reported that they often read books/articles related to effective teaching to improve classroom performance and rarely carry out small-scale research activities in classes to become better informed of learning/teaching processes.

Although cognitive strategies were reported to be the fourth most frequently used strategy by males in the current study $(60.2 \%)$, some reflective practices, such as small research activities in classrooms, were recorded to be rarely carried out (53.1\%). However, the female participants' fourth most used strategy was critical strategies (50.2\%), involving reflection through finding ways to build tolerance in classes and society as a whole. In detail, female instructors often think of ways to enable their students to change their social lives (i.e., gender bias), but they rarely include lessdiscussed topics, such as old age, minorities, and poverty.

Practical strategies were reported to be the least frequently used strategies by the female and male instructors (10.6\% and $23.9 \%$, respectively), with 161 out of 226 males rarely adopting this reflective practice, mainly writing about the accomplishments/failures of a lesson or talking about the experience to a colleague. In detail, female instructors reported that they often talk about their classroom experiences with their colleagues and seek their advice/feedback. Still, they rarely have a file where they keep accounts of teaching for reviewing purposes. On the other hand, male instructors often observe other instructors' classrooms to learn about their efficient practices, but rarely after each lesson; they write about that lesson's accomplishments/failures or talk about the experience to a colleague.

The final statistical analysis was conducted to answer the third research question: Does teaching experience significantly make a substantial variance in instructors' conscious reflection? An analysis comparing novice and experienced instructors revealed that experienced instructor participants $(M=3.36, S D=0.56)$ demonstrated a significantly higher score on the total ELTRI, $t(371)=-3.72, p<.001$, than novice instructor participants $(M=3.15, S D=0.41)$. Experienced instructor participants $(M=3.10, S D=0.72)$ demonstrated a significantly higher score on the ELTRI practical scores, $t(371)=-2.78, p=.006$, than novice instructor participants $(M=2.88, S D$ $=0.62)$. Experienced instructor participants $(M=3.57, S D=0.83)$ demonstrated a significantly higher score on the ELTRI cognitive scores, $t(371)=-6.22, p<.001$, than novice instructor participants $(M=3.03, S D=0.58)$. Experienced instructor participants $(M=3.69, S D=0.72)$ demonstrated a significantly higher score on the ELTRI metacognitive scores, $t(371)=-4.12, p<$ .001 , than novice instructor participants $(M=3.37, S D=0.64)$.

\section{Discussion}

This study examined the gender differences of in-service postsecondary EFL instructors' reflective teaching practice for professional development. Mainly this study centered on Kolb's (1984) experiential learning cycle, including four phases from problem finding to question inquiring, answer-seeking, and then active investigation that were investigated within male and 
female EFL instructors regarding conscious reflective teaching and the strategies that instructors mostly employ when reflecting on their practice. Moreover, the researchers examined whether teaching experience significantly affects instructors' conscious reflection among participants of both genders. The independent sample $t$-test for gender differences showed statistically significant results, indicating that females scored higher than males on the total ELTRI score. Contrary to the findings of Afshar and Farahani (2015) and Ring et al. (2016), who revealed that male EFL instructors outperformed their female counterparts regarding reflective teaching, this study confirmed that female EFL instructors scored higher than males on the scores for the practical, cognitive, and metacognitive factors of the ELTRI. Even though there is limited research on gender differences in reflection, this result is consistent with research indicating that females may have a stronger sense of efficacy than males because the teaching profession is mainly a female occupation (Gencer \& Cakiroglu, 2007).

Furthermore, this study showed that metacognitive strategies were the most frequently used strategies by males and females. Mainly, both male and female participants tried to explore their personalities as language instructors, define learning and teaching, and examine their teaching profession. This result is in line with Moghaddam et al.'s (2019) study, where they indicated that metacognitive and cognitive components are the instructors' most frequently used reflective techniques. Phelps et al. (2004) indicated that reflection and metacognitive learning processes are central to effective teaching practice and essential to lifelong learning. On the other hand, practical strategies were reported to be the least frequently used strategies by males and females. Precisely, both male and female participants rarely implemented written reflections (i.e., journal writing, lesson reports, action research, and teaching portfolios). This result is also consistent with Moghaddam et al.'s (2019) study, where they indicated that practical components are the instructors' least frequently used reflective techniques. Research has indicated that such reflective practices need active guidance to promote the development of reflective skills and ongoing practice. Candy et al. (1985) indicated that instructors or learners would not automatically engage in reflection unless taught and provided with subsequent reflective practice guidance. Furthermore, the instructor's busy workload could also act as a hindrance (Day, 1993) because writing reflections is beyond the instructors' job descriptions.

Results have also indicated that males scored higher than females on the critical factor of the ELTRI. Male participants considered the social, political, and cultural factors influential within their teaching context more than female participants. This result contradicts Akbari et al. (2010) study where critical reflection was neglected. Even though research has reported that critical and moral aspects of teaching are not widely covered during instructor education. Therefore, instructors might not be aware of their importance (Sanger \& Osguthorpe, 2011). This study's findings indicated that male participants were aware of critical reflection and outperformed female participants. However, because critical reflection requires in-depth thinking, instructors might need to be trained and taught how to reflect critically rather than simply be encouraged to reflect. Larrivee (2000) indicated that even at the early professional stages of teaching, critical reflection appears to be possible and helpful for the instructor's development.

Conclusively, the findings indicated that experienced instructor participants demonstrated a significantly higher score on the total ELTRI than novice instructor participants. This result ties well with Kolb's experiential learning model, where learning occurs when individuals encounter different experiences, reflect on such experiences, and show the ability to change by taking risks and improving actions (Kolb, 1984). This result is also in line with previous studies where experienced instructors were found to be more reflective than their novice counterparts (Dewaele et al., 2018; Faez \& Valeo, 2012; Moradkhani et al., 2017; Richards, 1998). Further the current 
results indicated that females scored higher than males on the total ELTRI scores, except on the critical factor of the ELTRI, where males outperformed. The results also revealed that experienced instructor participants had a significantly higher score on the total ELTRI than novice instructor participants. The current result is inconsistent with what has been found in previous research (e.g.., Bawaneh et al., 2020), indicating that there is a statistically significant difference among teachers in terms of gender and favor of males. Although extensive research has documented the importance of reflection in teaching and teacher education (LaBelle \& Belknap, 2016; Moghaddam et al., 2019; Yoshihara et al., 2020), research still has not provided substantial evidence regarding instructors' reflective teaching practices pertaining to gender differences and teaching Experience.

However, it is essential to note that the length of experience does not predictably give awareness of one's teaching practice and might only indicate repeated teaching practices (Aalto et al., 2019). For novice instructors to become thoughtful instructors, it is necessary to nurture reflection as they accumulate teaching experiences (Van Manen, 1994). One threat to instructors' growth is the limited focus on reflective practice. Once instructors internalize the routines of teaching practices, their chances of professional growth fade. They will repeat the same class material and content each time they teach without adapting new techniques and technologies to enhance the teaching process. Eventually, all reported factors in this study should justify the existence of differences among instructors in terms of reflective practice for professional development and call for further exploration.

\section{Conclusion}

Promoting quality in education and empowering instructors' awareness of reflective strategies is essential to instructors' learning and professional development. Even though reflection and reflective practices are integral to teacher education, limited research has been devoted to reporting reflective practice actions and addressing gender differences, primarily when English is taught as a foreign language. Therefore, a quantitative research design using a survey adapted from Akbari et al. (2010) was initiated to investigate the difference between male and female EFL instructors regarding conscious reflective teaching and the strategies that instructors primarily utilize when reflecting on their practice. Moreover, this study examined whether teaching experience makes a substantial variance in instructors' conscious reflection among participants of both genders. This study's main result indicated that females scored higher than males on the total ELTRI scores, except on the critical factor of the ELTRI, where males outperformed. The results also revealed that experienced instructor participants demonstrated a significantly higher score on the total ELTRI than novice instructor participants. This study's findings will benefit instructors, instructional designers, and administrators interested in promoting instructors' professional development.

Beyond the results of this research, it is critical to report on the limitation of this study. The current study implemented a quantitative method of collecting and analyzing the data. However, existing research favors the use of both qualitative and quantitative methods "to draw from the strengths and minimize the weaknesses of both in single research studies and across studies" (Johnson \& Onwuegbuzie, 2004, p. 15). Therefore, qualitative methods are suggested to inspect behavioral aspects through ongoing evaluation of classroom observation, artifact assortments, and interview sessions to discuss claims further. It is also worthy to note that the EFL context where the study took place implements gender segregation in universities and colleges. The strictness of such segregation differs from one Saudi university to the other (Alrashidi, \& Phan, 2015). 
Moreover, this sample of university EFL instructors in Saudi Arabia may not be representative enough to generalize the data. Therefore, similar studies should be conducted with different instructors from different educational contexts to ratify this finding's generalizability within the EFL contexts. Expanding the sample scope with other divergent contexts and encompassing the future experiments' duration to capture sustained reflective occurrences are suggested. Future research should also consider the influence of other factors, such as the academic degree of EFL instructors, cultural background, and linguistic differences that might affect the instructors' knowledge and reflective practice. Further, although not directly linked, the "lack of time due to the burden of academic and administrative charges put on teachers may be regarded as another extraneous factor that may hamper any form of educational critical thinking and reflection" (Bawaneh, et al., p. 709). Looking forward, further efforts could prove relatively valuable to the literature. On a practical level, this study has some implications as we consider the education of international instructors:

- The standardization and regulation of the institutions need to be revisited to meet the developmental process experienced by the instructors.

- The establishment of a teacher preparation program needs to be monitored and supported to help provision gender differences.

- Policymakers in higher institutions should prepare systematic programs and provide remedial resources and events for instructors to target the most challenging areas for both genders.

- The institutional and social contexts need to be examined within which instructors can succeed as critical practitioners and coaches.

- The study suggests that the reflective practices of applied, cognitive, affective, metacognitive, and critical reflection offer much-needed assistance to counter gender differences by providing a tangible, flexible resource for reflective analysis.

Online teaching and learning environments should be explored to discover new pedagogical methods, such as encouraging participatory, inquiry-based social learning practices (Kreber \& Kanuka, 2006) that promote teaching and learning. Therefore, this study further calls for more explorations of online reflective strategies to allow both instructors and learners to engage in a successful transformative teaching and learning process. Support and development programs are also encouraged to help instructors engage in the online reflection within their unique teaching contexts. 


\section{Acknowledgments}

The authors would like to thank Prince Sultan University (PSU) for funding this research project under grant number IRB-CH-2020-6-1 and in affiliation with the Educational Research Lab. In addition, this paper was supported by Imam Mohammad Ibn Saud Islamic University (IMSIU).

\section{References}

Aalto, E., Tarnanen, M., \& Heikkinen, H. L. (2019). Constructing a pedagogical practice across disciplines in preservice teacher education. Teaching \& Teacher Education, 85, 69-80. https://doi.org/10.1016/j.tate.2019.06.006

Afshar, H. S., \& Farahani, M. (2015). Reflective thinking and reflective teaching among Iranian EFL teachers: Do gender and teaching experience make a difference. Procedia-Social \& behavioral sciences, 192(156), 615-620. https://doi.org/10.1016/j.sbspro.2015.06.107

Akbari, R. (2007). Reflections on reflection: A critical appraisal of reflective practices in L2 teacher education. System, 35(2), 192-207. https://doi.org/10.1016/j.system.2006.12.008

Akbari, R., Behzadpoor, F., \& Dadvand, B. (2010). Development of English language teaching reflection inventory. System, 38(2), 211-227. https://doi.org/10.1016/j.system.2010.03.003

Aldahmash, A. H., Alshmrani, S. M., \& Almufti, A. N. (2017). Secondary school science teachers' views about their reflective practices. Journal of Teacher Education for Sustainability, 19(1), 43-53. https://doi.org/10.1515/jtes-2017-0003

Alrashidi, O., \& Phan, H. (2015). Education context and English teaching and learning in the Kingdom of Saudi Arabia: An overview. English Language Teaching, 8(5), 33-44. http://dx.doi.org/10.5539/elt.v8n5p33

Bawaneh, A. K., Moumene, A. B. H., \& Aldalalah, O. (2020). Gauging the level of reflective teaching practices among science teachers. International Journal of Instruction, 13(1), 695712. https://doi.org/10.29333/iji.2020.13145a

Biggs, J. (1999). What the student does: Teaching for enhanced learning. Higher Education Research \& Development, 18(1), 57-75. https://doi.org/10.1080/0729436990180105

Bloom, B. S. (1956). Taxonomy of educational objectives. Book 1 (2nd ed.). Cognitive domain. McKay.

Burhan-Horasanl1, E., \& Ortaçtepe, D. (2016). Reflective practice-oriented online discussions: A study on EFL teachers' reflection-on, in and for-action. Teaching and Teacher Education, 59, 372-382. https://doi.org/10.1016/j.tate.2016.07.002

Candy, P., Harri-Augstein, S., \& Thomas, L. (1985). Reflection and the self-organized learner: A model of learning conversations. In D. Boud, R. Keogh, \& D. Walker (Eds.), Reflection: Turning experience into learning (pp. 100-116). Kogan Page.

Darling-Hammond, L., Flook, L., Cook-Harvey, C., Barron, B., \& Osher, D. (2020). Implications for educational practice of the science of learning and development. Applied Developmental Science, 24(2), 97-140. https://doi.org/10.1080/10888691.2018.1537791

Day, C. (1993). Reflection: a necessary but not sufficient condition for professional development. British Educational Research Journal, 19(1), 83-93. http://dx.doi.org/10.1080/0141192930190107

Dewaele, J. M., Gkonou, C., \& Mercer, S. (2018). Do ESL/EFL teachers' emotional intelligence, teaching experience, proficiency and gender affect their classroom practice?. In Emotions 
in second language teaching (pp. 125-141). Springer, Cham. https://doi.org/10.1007/9783-319-75438-3_8

Dewey, J. (1931). Philosophy and civilization. Minton, Balch \& Company.

Dyches, J., \& Boyd, A. (2017). Foregrounding equity in teacher education: Toward a model of social justice pedagogical and content knowledge. Journal of Teacher Education, 68(5), 476-490. https://doi.org/10.1177/0022487117705097

Easton, C. (2018). Women and 'the philosophical personality': Evaluating whether gender differences in the Cognitive Reflection Test have significance for explaining the gender gap in Philosophy. Synthese, 198, 1-29. https://10.1007/s11229-018-01986-w

Everett, M. C. (2013). Reflective journal writing and the first-year experience. International Journal of Teaching and Learning in Higher Education, 25(2), 213-222. http://www.isetl.org/ijtlhe

Faez, F., \& Valeo, A. (2012). TESOL teacher education: Novice teachers' perceptions of their preparedness and efficacy in the classroom. TESOL Quarterly, 46(3), 450-471. http://dx.doi.org/10.1002/tesq.37

Farrell, T. S. C. (2004). Reflective practice in action: 80 reflections breaks for busy teachers. Corwin Press.

Farrell, T. S. C. (2009). The novice teacher experience. In A. Burns \& J. C. Richards (Eds.), The Cambridge guide to second language teacher education (pp. 182-189). Cambridge University Press.

Farrell, T. S. C. (2012). Novice-service language teacher development: Bridging the gap between preservice and in-service education and development. TESOL Quarterly, 46(3), 435-449. http://dx.doi.org/10.1002/tesq.36

Farrell, T. S. C. (2015). It's not who you are! It's how you teach! Critical competencies associated with effective teaching. RELC Journal, 46(1), 79-88. https://doi.org/10.1177/0033688214568096

Farrell, T. S., \& Kennedy, B. (2019). Reflective practice framework for TESOL teachers: One teacher's reflective journey. Reflective $\quad$ Practice, 20(1), 1-12. https://doi.org/10.1080/14623943.2018.1539657

Fendler, L. (2003). Teacher reflection in a hall of mirrors: Historical influences and political reverberations. Educational Researcher, 32(3), 16-25. https://doi.org/10.3102/0013189X032003016

Gencer, A. S., \& Cakiroglu, J. (2007). Turkish preservice science teachers' efficacy beliefs regarding science teaching and their beliefs about classroom management. Teaching \& Teacher Education, 23(5), 664-675. https://doi.org/10.1016/j.tate.2005.09.013

Harland, D. J., \& Wondra, J. D. (2011). Preservice teachers' reflection on clinical experiences: A comparison of blog and final paper assignments. Journal of Digital Learning in Teacher Education, 27(4), 128-133. https://doi.org/10.1080/21532974.2011.10784669

Hoban, G. (2000). Using a reflective framework to study teaching-learning relationships. Reflective practice, 1(2), 165-182. https://doi.org/10.1080/713693148

Jay, J. K., \& Johnson, K. L. (2002). Capturing complexity: A typology of reflective practice for teacher education. Teaching \& Teacher Education, 18(1), 73-85. https://doi.org/10.1016/s0742-051x(01)00051-8

Johnson, R. B., \& Onwuegbuzie, A. J. (2004). Mixed methods research: A research paradigm whose time has come. Educational Researcher, 33(7), 14-26. https://doi.org/10.3102/0013189x033007014 
Khazaie, Z. M., \& Mesbah, Z. (2014). The relationship between extrinsic vs. intrinsic motivation and strategic use of language of Iranian intermediate EFL learners. Theory \& Practice in Language Studies, 4(1), 99-109. https://doi.org/10.4304/tpls.4.1.99-109

Knapp, N. F. (2012). Reflective journals: Making constructive use of the "apprenticeship of observation" in preservice teacher education. Teaching Education, 23(3), 323-340. Hata! Köprü başvurusu geçerli değil.https://doi.org/10.1080/10476210.2012.686487

Kolb, D. A. (1984). The process of experiential learning. In D. A. Kolb (Ed.), Experiential learning: Experience as the source of learning and development. (pp. 20-38). Prentice-Hall, Inc.

Kolb, D. A. (2015). Experiential learning: Experience as the source of learning and development. FT press.

Kollmayer, M., Schober, B., \& Spiel, C. (2018). Gender stereotypes in education: Development, consequences, and interventions. European Journal of Developmental Psychology, 15(4), 361-377. https://doi.org/10.1080/17405629.2016.1193483

Kreber, C., \& Kanuka, H. (2006). The scholarship of teaching and learning and the online classroom. Canadian Journal of University Continuing Education, 32(2), 109-131. https://doi.org/10.21225/D5P30B

LaBelle, J. T., \& Belknap, G. (2016). Reflective journaling: Fostering dispositional development in preservice teachers. Reflective Practice, 17(2), 125-142. https://doi.org/10.1080/14623943.2015.1134473

Larrivee, B. (2000). Transforming teaching practice: Becoming the critically reflective teacher. Reflective Practice, 1(3), 293-307. https://doi.org/10.1080/713693162

Lundgren, H., Bang, A., Justice, S. B., Marsick, V. J., Poell, R. F., Yorks, L., Clark, M., \& Sung, S. (2017). Conceptualizing reflection in experience-based workplace learning. Human Resource Development International, 20(4), 305-326. https://doi.org/10.1080/13678868.2017.1308717

Moghaddam, R. G., Davoudi, M., Adel, S. M. R., \& Amirian, S. M. R. (2019). Reflective teaching through journal writing: A study on EFL teachers' reflection-for-action, reflection-inaction, and reflection-on-action. English Teaching \& Learning, 44(3), 277-296. https://doi.org/10.1007/s42321-019-00041-2

Moradkhani, S., Raygan, A., \& Moein, M. S. (2017). Iranian EFL teachers' reflective practices and self-efficacy: Exploring possible relationships. System, 65, 1-14. Hata! Köprü başvurusu geçerli değil.https://doi.org/10.1016/j.system.2016.12.011

Oxford, R., \& Nyikos, M. (1989). Variables affecting choice of language learning strategies by university students. The Modern Language Journal, 73(3), 291-300. https://doi.org/10.1111/j.1540-4781.1989.tb06367.x

Pedro, J., Abodeeb-Gentile, T., \& Courtney, A. (2012). Reflecting on literacy practices: Using reflective strategies in online discussion and written reflective summaries. Journal of Digital Learning in Teacher Education, 29(2), 39-47. https://doi.org/10.1080/21532974.2012.10784703

Phelps, R., Graham, A., \& Kerr, B. (2004). Teachers and ICT: Exploring a metacognitive approach to professional development. Australasian Journal of Educational Technology, 20(1). https://doi.org/10.14742/ajet.1367

Primi, C., Donati, M. A., Chiesi, F., \& Morsanyi, K. (2018). Are there gender differences in cognitive reflection? Invariance and differences related to mathematics. Thinking \& Reasoning, 24(2), 258-279. https://doi.org/10.1080/13546783.2017.1387606

Richards, J. C. (1998). Beyond training: Perspectives on language teacher education. Cambridge University Press. 
Richards, J. C., \& Farrell, T. S. C. (2005). Professional development for language teachers: Strategies for teacher learning. Ernst Klett Sprachen.

Richert, A. E. (1990). Teaching teachers to reflect: A consideration of programme structure. $\begin{array}{llll}\text { Journal of } & \text { Curriculum }\end{array}$ https://doi.org/10.1080/0022027900220601

Ring, P., Neyse, L., David-Barett, T., \& Schmidt, U. (2016). Gender differences in performance predictions: Evidence from the cognitive reflection test. Frontiers in Psychology, 7, 1680. https://10.3389/fpsyg.2016.01680/full

Rodgers, C. (2002). Defining reflection: Another look at John Dewey and reflective thinking. Teachers College Record, 104(4), 842-866. https://doi.org/10.1111/1467-9620.00181

Sanger, M. N., \& Osguthorpe, R. D. (2011). Teacher education, preservice teacher beliefs, and the moral work of teaching. Teaching \& Teacher Education, 27(3), 569-578. https://doi.org/10.1016/j.tate.2010.10.011

Schön, D. A. (1987). Educating the reflective practitioner: Toward a new design for teaching and learning in the professions. Jossey-Bass.

Schön, J. (1983). Petrophysik: Physikalische eigenschaften von gesteinen und mineralen [Petrophysics: Physical properties of glands and minerals]. Akademie-Verlag.

Sifakis, N. (2007). The education of teachers of English as a lingua franca: A transformative perspective. International Journal of Applied Linguistics, 17(3), 355-375. https://doi.org/10.1111/j.1473-4192.2007.00174.x

Trizano-Hermosilla, I., \& Alvarado, J. M. (2016). Best alternatives to Cronbach's alpha reliability in realistic conditions: congeneric and asymmetrical measurements. Frontiers in psychology, 7, 769. https://doi.org/10.3389/fpsyg.2016.00769

Tsui, A. B. M. (2005). Understanding expertise in teaching: Case studies in ESL. Cambridge University Press.

Tsui, A. B. M. (2009). Distinctive qualities of expert teachers. Teachers and Teaching: Theory \& Practice, 15(4), 421-439. https://doi.org/10.1080/13540600903057179

Van Manen, M. (1994). Pedagogy, virtue, and narrative identity in teaching. Curriculum Inquiry, 24(2), 135-170. https://doi.org/10.1080/03626784.1994.11076157

Vaske, J. J., Beaman, J., \& Sponarski, C. C. (2017). Rethinking internal consistency in Cronbach's alpha. Leisure Sciences, 39(2), 163-173. https://doi.org/10.1080/01490400.2015.1127189

Yoshihara, R., Kurata, A., \& Yamauchi, A. (2020). Reflective journals to explore struggles and difficulties of novice Japanese EFL university instructors. Reflective Practice, 21(1), 8193. https://doi.org/10.1080/14623943.2019.1708714

Zeichner, K. M., \& Liston, D. P. (1996). Reflective teaching: An introduction. Erlbaum.

\section{Notes on Contributors}

Dr. Norah Almusharraf is an assistant professor in Applied Linguistics, Prince Sultan University, Riyadh, Kingdom of Saudi Arabia. She received her Ph.D. degree in Foreign and Second Language Education from the University of Buffalo. Her professional and research interests focus on English as a foreign language (EFL) learning pedagogics, inquiry-based teaching and learning, project-based learning and content-based instruction, cultural magnitudes of foreign/second language teaching and learning classroom, multimodal assessment and teaching strategies, technology implantation in the EFL English classrooms, teacher professional development using class critique and through professional learning community (PLC). 
Dr. Asma Almusharraf is an assistant professor in the College of Languages and Translation at Imam Mohammad Ibn Saud Islamic University (IMSIU), Riyadh, Kingdom of Saudi Arabia. She gained her Ph.D. in Applied Linguistics with the first degree of honor. Her research interest includes Language Acquisition, Foreign Language Teaching and Learning, ComputerAssisted Language Learning and Professional Development. 